\title{
Fetal lipopolysaccharide exposure modulates diet-dependent gut maturation and sensitivity to necrotising enterocolitis in pre-term pigs
}

\author{
Malene S. Cilieborg ${ }^{1,2}$, Mette Schmidt ${ }^{3}$, Kerstin Skovgaard ${ }^{2}$, Mette Boye ${ }^{2}$, Nicolai R. Weber ${ }^{3}$, \\ Peter M. Heegaard ${ }^{2}$, Douglas G. Burrin ${ }^{4}$ and Per T. Sangild ${ }^{1 *}$ \\ ${ }^{1}$ Department of Human Nutrition, Faculty of Life Science, University of Copenhagen, 30 Rolighedsvej, DK-1958 \\ Frederiksberg C, Denmark \\ ${ }^{2}$ Division of Veterinary Diagnostics and Research, National Veterinary Institute, Technical University of Denmark, DK-1790 \\ Copenhagen, Denmark \\ ${ }^{3}$ Department of Large Animals, Faculty of Life Science, University of Copenhagen, 30 Rolighedsvej, DK-1870 Frederiksberg C, \\ Denmark \\ ${ }^{4}$ USDA Children's Nutrition Research, Baylor College of Medicine, Houston, TX, USA \\ (Received 1 July 2010 - Revised 18 December 2010 - Accepted 20 January 2011 - First published online 17 May 2011)
}

\begin{abstract}
Uterine infections during pregnancy predispose to pre-term birth and postnatal morbidity, but it is unknown how prenatal bacterial exposure affects maturation of the immature gut. We hypothesised that a prenatal exposure to gram-negative lipopolysaccharide (LPS) has immunomodulatory effects that improve resistance towards necrotising enterocolitis (NEC) in pre-term neonates. At approximately $85 \%$ gestation, pig fetuses were injected intramuscularly with saline or LPS $(0 \cdot 014 \mathrm{mg} / \mathrm{kg})$, or intra-amniotically with LPS (0.4 mg/kg). Pigs were delivered by caesarean section 3-5d later and fed colostrum (C) or formula (F) for $48 \mathrm{~h}$. Gut indices did not differ between pigs injected intramuscularly with saline or LPS, and these groups were therefore pooled into two control groups according to diet (control-F, $n 32$ and control-C, $n$ 11). Control-F pigs showed reduced villus heights, mucosal structure, gut integrity, digestive enzymes, elevated NEC incidence $(38 v .0 \%, P<0.05)$ and several differentially expressed immune-related genes, relative to control-C pigs. Compared with the control-F and control-C groups, values in formula-fed pigs given intra-amniotic LPS formula ( $n$ 17) were intermediate for villus height, enzyme activities, intestinal permeability and NEC incidence ( $18 \%, P=0 \cdot 2$ relative to control-F), and numbers of differentially expressed immune genes. In conclusion, prenatal exposure of the fetal gut to Gram-negative bacteria may modulate the immediate postnatal response to an enteral diet and colonising bacteria.
\end{abstract}

Key words: Fetal surgery: Premature birth: Intestinal inflammation

Uterine infection during pregnancy predisposes to pre-term birth and may be associated with an increased overall neonatal morbidity. It remains unclear, however, how prenatal bacterial stimulation (systemic or luminal) affects the sensitivity to inflammatory responses and necrotising enterocolitis (NEC) in the intestine of pre-term neonates ${ }^{(1-4)}$. The immature intestine may show an increased expression of the toll-like receptor (TLR)-4 to Gram-negative lipopolysaccharide (LPS), leading to an exaggerated pro-inflammatory response via the NF-кB pathway ${ }^{(5,6)}$. In the immediate postnatal period of term neonates, this innate immune response to LPS is down-regulated, facilitating mucosal tolerance towards Gram-negative bacteria and general bacterial colonisation ${ }^{(5,6)}$.
Insufficient developmental down-regulation of the TLR-4mediated response to Gram-negative bacterial stimuli may at least in part explain the exaggerated inflammatory response leading to NEC in pre-term neonates.

An early exposure to bacterial stimuli may have the potential to enhance epithelial immune development, as suggested by improved postnatal lung maturation and the reduced respiratory distress syndrome following uterine infection in human pregnancy ${ }^{(7-9)}$. Correspondingly, intra-amniotic LPS (LPSa) or IL-1 injection of fetal lambs, mimicking a uterine infection, is associated with an increased number of inflammatory cells in the amniotic and lung fluid, increased surfactant production and increased compliance and lung gas

Abbreviations: C, colostrum; control-C, control-colostrum; F, formula; control-F, control-formula; LPS, lipopolysaccharide; LPSa, intra-amniotic lipopolysaccharide; LPSa-F, intra-amniotic lipopolysaccharide formula; NEC, necrotising enterocolitis; TLR, toll-like receptor. 
volume $e^{(10-12)}$. The effect was a result of direct epithelial stimulation when the fetus inhaled and swallowed the amniotic fluid with bacterial and inflammatory compounds ${ }^{(11)}$. A corresponding epithelial stimulation and increased structural, functional and immunological development could occur in the gastrointestinal tract and affect the NEC susceptibility of the immature intestine. A systemic stimulation with relatively high doses of LPS was associated with acidosis and death in fetal lambs ${ }^{(11)}$ and with NEC in pigs and rats ${ }^{(13,14)}$, indicating that the route of bacterial exposure (luminal or systemic) may influence the postnatal response. Such proinflammatory responses may be modified by diet just after birth as shown in pre-term pigs, where the mother's colostrum with its high concentrations of trophic and immunomodulatory compounds stimulates gut function and suppresses pro-inflammatory mediators and NEC development relative to formula ${ }^{(15-18)}$. A pre-term neonate subjected to prenatal systemic infection may thus benefit from colostrum feeding to counteract the pro-inflammatory bacterial insults.

Given this background, the present study was designed to test whether LPS administration to fetal piglets affects gut development and immunological responses just after birth, and how different diets (formula or colostrum) may influence this response. Based on the effects reported previously for neonatal lung function in lambs, we hypothesised that prenatal LPSa stimulation of fetal pigs would improve gut development, modulate the pro-inflammatory responses and improve bacterial tolerance, and thereby reduce the diet-dependent NEC sensitivity of the immature intestine. Conversely, we hypothesised that intramuscular LPS injections might increase
NEC sensitivity. In the present initial study, we tested relatively low doses of intramuscular and LPSa, considering the high risk of premature labour and fetal death following intra-fetal surgery and LPS administration in late gestation. Structural, functional and immunological indices of the gut tissue were measured to identify the effects of intra-fetal LPS administration as well as of the postnatal diet.

\section{Methods and materials}

\section{Prenatal surgery and lipopolysaccharide injections}

All procedures in the animal protocol mentioned below were approved by the National Committee on Animal Experimentation, Denmark. At $85-87 \%$ gestation, five pregnant sows (Large White $\times$ Danish Landrace) underwent laparatomy after sedation (azaperone), anaesthesia (propofol and isoflurane after intubation) and systemic (fentanyl) and local (lidocaine) analgesia treatment. The uterus was exposed, and in total seventy-two live fetuses were injected with saline or LPS from Escherichia coli serotype K-235 (Sigma-Aldrich, St Louis, MO, USA) through the uterine wall (Fig. 1). Fetuses (estimated body weights $1.0 \mathrm{~kg}$ ) were injected intramuscularly in the hind leg with either $0.5 \mathrm{ml}$ saline $(n 27)$ or $0.5 \mathrm{ml}$ lowdose LPS $(0.014 \mathrm{mg} ; n$ 23), or they were injected into the amniotic fluid via the oral cavity with $1 \mathrm{ml}$ high-dose LPS (total $0.4 \mathrm{mg}, n 22$ ). Each pig was chipped for postnatal recognition, and the uterus and fetuses were put back into the abdominal cavity and the flank was closed by sutures. The sows were returned to the stables and treated daily with broad-spectrum antibiotics (amoxycillin intramuscularly) and

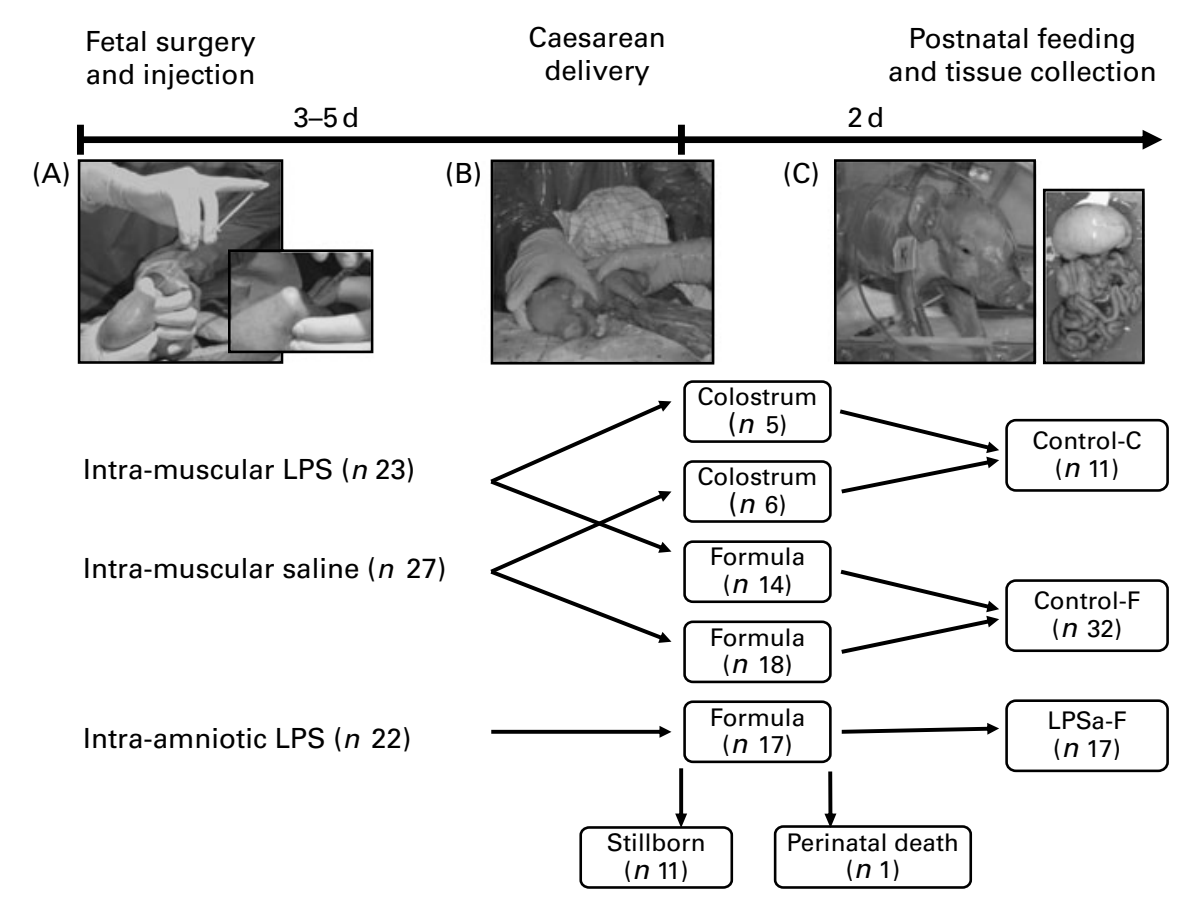

Fig. 1. Schematic overview of the fetal interventions and the groups of postnatal pre-term pigs. Pig fetuses received saline or lipopolysaccharide (LPS) injections (intra-amniotic or intramuscular, (A)) 3-5d before pre-term delivery by caesarean section (B) and fed colostrum (C) or formula (F) for $2 \mathrm{~d}$ postnatally (C). For the tissue analyses, data from the intramuscular saline and LPS groups were pooled according to the diet (control-C and control-F) and compared with formula-fed pigs receiving intra-amniotic LPS (LPSa-F). 
progesterone $(50 \mathrm{mg})$ to avoid infections and spontaneous birth before caesarean delivery.

\section{Caesarean section and postnatal feeding protocol}

Caesarean section was planned to take place no later than $7 \mathrm{~d}$ after the fetal surgery, unless signs of pre-term labour developed beforehand, leading to sedation, anaesthesia and immediate caesarean delivery as described earlier ${ }^{(15,16)}$. A total of sixty-one pigs were delivered and immediately transferred to temperature- and oxygen-regulated incubators (Air-Shields, Hatboro, PA, USA). Of the sixty-one pigs, one died soon after birth from complications not related to NEC, leaving sixty pigs to be included in the final analyses. Blood samples were drawn from the umbilical cord at caesarean section and at $6 \mathrm{~h}$ after birth, and from the heart at euthanasia to measure blood gases, and plasma haptoglobin and cortisol, as described previously ${ }^{(15,16)}$

Following our standard rearing and feeding protocol ${ }^{(15,16)}$, the pigs were fitted with orogastric catheters (6F; Pharmaplast, Roskilde, Denmark) and fed full enteral nutrition $(15 \mathrm{ml} / \mathrm{kg}$ per $3 \mathrm{~h}$ ) for $2 \mathrm{~d}$ until euthanasia (pentobarbitone: $60 \mathrm{mg} / \mathrm{kg}$, intravenously) and tissue collection. Pigs injected intramuscularly were fed either cows' colostrum ( $n 6$ for saline and $n 5$ for LPS injection, respectively) or infant formula ( $n 18$ for saline and $n 14$ for LPS injection, respectively) (Fig. 1). All pigs given LPSa were fed formula after birth ( $n$ 17). The formula was made of three commercial products (per litre of water: $80 \mathrm{~g}$ Pepdite 2-0, $70 \mathrm{~g}$ Maxipro and $75 \mathrm{ml}$ LiquigenMCT, kindly donated by SHS International, Liverpool, Merseyside, UK). The macronutrient content was designed to match the composition of sows' milk and contained per litre of formula: energy, $4140 \mathrm{~kJ}$; protein (mainly whey protein), $64 \mathrm{~g}$; carbohydrate (mainly glucose), $45 \mathrm{~g}$; fat, $61 \mathrm{~g}$ (saturated, $44 \mathrm{~g}$; monounsaturated $10 \mathrm{~g}$; polyunsaturated, $4 \mathrm{~g}$ ); Na, 0.30 g; $\mathrm{K}, 0.64 \mathrm{~g} ; \mathrm{Ca}, 0.59 \mathrm{~g} ; \mathrm{P}, 0.42 \mathrm{~g}^{(15)}$. Bovine colostrum was collected as the first milking after parturition from dairy cows (Holstein Friesian, Gjordslev Gods, Denmark) and diluted with $30 \%$ water to achieve an energy content similar to that in the formula.

\section{Clinical evaluation and tissue collection}

Pigs were checked every $3 \mathrm{~h}$ for NEC symptoms (bloody diarrhoea, lethargy, respiratory distress and abdominal distension). When these symptoms were evident, pigs were euthanised and tissue was collected. All remaining pigs were euthanised on day 3 ( $41-57 \mathrm{~h}$ postpartum). We evaluated five gastrointestinal regions (stomach, proximal, mid and distal small intestine and colon) for NEC lesions and scored 1-6 according to our standard macroscopic NEC pathology evaluation: (1) absence of lesions; (2) local hyperaemia, inflammation and oedema; (3) hyperaemia, extensive oedema and local haemorrhage; (4) extensive haemorrhage; (5) local necrosis and pneumatosis intestinalis; (6) extensive necrosis and pneumatosis intestinalis ${ }^{(15)}$. NEC was defined as a score of minimum 3 in minimum of one region. Organs (stomach, small intestine, colon, liver, spleen, kidneys, lungs and heart) were weighed, and the tissues from three small-intestinal regions and from the liver were sampled and snap-frozen for functional and immunological analyses. Samples from the distal small intestine were formaldehydefixed and paraffin-embedded to investigate mucosal structures. Degree of lung expansion was determined as lung density (weight/volume), with volume recorded by water displacement.

\section{Mucosal permeability, villus structure and digestive function}

Intestinal permeability was tested, as described previously ${ }^{(15)}$, as the post-mortem urine ratio of lactulose and mannitol after oral administration of the two sugars $(0.5$ and $0.3 \mathrm{~g} / \mathrm{kg}$, respectively) $4 \mathrm{~h}$ before euthanasia. Dimensions of villi, crypts and non-mucosal tissue (submucosa, lamina muscularis and serosa) in the distal small intestine were measured (SoftWoRx Explorer version 1.1; Applied Precision, Issaquah, WA, USA) on scanning pictures obtained with an ArrayWoRx ${ }^{\mathrm{e}}$ microarray scanner (Applied Precision). The activity of mucosal disaccharidases and peptidases was analysed as described previously ${ }^{(16)}$.

\section{Systemic and mucosal immune parameters}

Plasma levels of the acute-phase protein, haptoglobin, at birth, $6 \mathrm{~h}$ and at euthanasia were determined by a sandwich ELISA using an in-house mouse anti-porcine haptoglobin monoclonal catching antibody and a commercial rabbit antihuman haptoglobin detection antibody (DAKO A0030; DAKO, Glostrup, Denmark), as described previously ${ }^{(19)}$.

Gene expression in the distal small intestine and liver was investigated by an in-house immune-focused mRNA Micro Array POM4 chip with 373 oligonucleotides, representing more than 250 different genes (platform accession no. GPL7576) following the procedures described previously ${ }^{(20)}$. In short, total RNA was extracted (RNeasy Midi Kit with TRIzol reagent; Qiagen, Ballerup, Denmark) from the tissues from saline-injected formula-fed pigs ( $n$ 9), saline-injected colostrum-fed pigs $(n$ 5) and LPSa-injected formula-fed pigs ( $n$ 8). RNA quality and quantity were determined on a Nano Chip 6000, Agilent 2100 bioanalyser (Agilent Technologies, Nærum, Denmark) and on a Nanodrop ND-1000 spectrophotometer (Saveen and Werner AB, Limhamn, Sweden), respectively, before cDNA synthesis (QuantiTect Reverse Transcription Kit; Qiagen). Samples and a reference pool of all samples were labelled (Oyster 550 and 650, respectively) using 3DNA Array 900 expression array detection kits (Genisphere, Hatfield, PA, USA). Hybridisation, washing and scanning were performed as described previously ${ }^{(20)}$. Images were processed in GenePixPro 6.0 (Molecular Devices Corporation, Sunnyvale, CA, USA) and analysed using Acuity 4.0 (Molecular Devices Corporation), revealing pairwise differences in gene expression among treatment groups and between sick and healthy pigs.

Tissue levels of TLR-4, IL-1 receptor-associated kinase- 1 and IкB were investigated by immunoblotting analysis as 
Table 1. List of antibodies used for Western blotting

\begin{tabular}{llll}
\hline Target protein $($ size $)$ & Type & Dilution & Manufacturer \\
\hline TLR4 $(89 \mathrm{kDa})$ & Mouse monoclonal & $1: 200$ & GenWay, San Diego, CA, USA \\
IRAK1 $(80 \mathrm{kDa})$ & Rabbit polyclonal & $1: 1000$ & Santa Cruz Biotechnology, Inc., Santa Cruz, CA, USA \\
IKB- $\alpha(39 \mathrm{kDa})$ & Rabbit polyclonal & $1: 1000$ & Cell Signaling Technology, Beverly, MA, USA \\
\hline
\end{tabular}

TLR, toll-like receptor; IRAK1, IL-1 receptor-associated kinase-1.

described previously ${ }^{(21)}$ by separation on denatured SDS-PAGE gels ( $7 \%$ for TLR- 4 and IL-1 receptor-associated kinase-1 (IRAK1), and 15\% for IкB) and overnight incubation with a primary antibody (Table 1) on nitrocellulose membranes followed by $1 \mathrm{~h}$ incubation with a secondary antibody (goat anti-rabbit IgG-horseradish peroxidase or goat anti-mouse IgG-horseradish peroxidase, 1:5000; Santa Cruz Biotechnology, Inc.). Blots were visualised with the horseradish peroxidase substrate (ECL-plus; Amersham Biosciences, Piscataway, NJ, USA), scanned and quantified by ImageQuant 5.0 software (Molecular Dynamics; Amersham Biosciences, Sunnyvale, CA, USA).

Activity of NF- $\mathrm{KB}$ was determined on nuclear extracts from the distal small intestine using the TransAM p65 NF-кB Transcriptions Factor Assay Kit (Active Motif, Carlsbad, CA, USA). Following the manufacturer's protocol, nuclear extracts were obtained, and duplicates of $2-20 \mu \mathrm{g}$ protein were added into the ninety-six-well plate together with different dilutions of the manufacturer's positive control. After incubation with the NF- $\mathrm{BB}$ p 65 antibody, detection with a secondary antibody and development, following the manufacturer's protocol, absorbance was read on a SpectraMax 340 microplate spectrophotometer (Molecular Devices Corporation) at 450 and $655 \mathrm{~nm}$.

\section{Calculations and statistical analyses}

All results are presented as means with their standard errors. Group differences in NEC incidences were tested using Fisher's exact test (SAS/STAT version 9.1; SAS Institute, Cary, NC, USA). The PROC MIXED procedure of a two-way ANOVA of SAS, with treatment, diet and sex as fixed variables, and pigs and sows as random variables, was used to test the mean differences among treatment groups and between pigs with and without NEC for all remaining parameters. After the initial analyses showing no effect of intramuscular LPS injections, we used for the additional analyses a reduced model incorporating only diet (colostrum and formula), sex and LPS (with or without amniotic LPS administration) as the fixed effects. mRNA microarray data were analysed in Acuity 4.0 (Molecular Devices Corporation) as described earlier. Differences in the number of differentially regulated genes after Acuity treatment comparisons were tested using Fisher's exact test (SAS). For all analyses, $P=0.05$ was used as the critical level of significance.

\section{Results}

\section{Clinical outcomes}

All five sows showed signs of labour $3-5 \mathrm{~d}$ after the fetal surgery, leading to immediate caesarean delivery. Survival of the injected pigs was high for four of the sows with only one or two stillborns, while eight of the fifteen pigs from one sow were stillborn. A total of sixty viable pigs were included in the further study (Fig. 1). Gestational age at delivery was 101-106 d among the five litters, and the mean birth weight was $0.9-1.3 \mathrm{~kg}$ across the litters. Cortisol levels at birth did not differ among litters or treatment groups (73.2 (SEM $2 \cdot 4) \mathrm{ng} / \mathrm{ml}$ ). The mean postnatal lifetime was $46 \cdot 1$ (SEM 1.2) h.

The clinical, structural, functional and immunological parameters shown in Table 2 did not differ among the groups of pigs that received intramuscular injections with saline or LPS for any of the diet groups (colostrum and formula). Hence, the intramuscular LPS dose appeared to be too low to elicit any significant effects, and for each diet, we pooled pigs given intramuscular LPS or saline in utero to form two larger control groups according to diet (control-colostrum (control-C), $n 11$ and control-formula (control-F), $n$ 32; Fig. 1). The pigs given the higher LPSa dose, LPSa-formula (LPSa-F, $n$ 17), remained a separate group, as these pigs differed in several clinical and functional parameters from the control-F and control-C groups. At the time of tissue collection, none of the control-C pigs had any NEC lesions in the gastrointestinal organs. NEC incidence in the LPSa-F group was $18 \%$ (three out of seventeen) $v$. 38\% (twelve out of thirty-two) in the control-F group $(P=0 \cdot 2)$, while the NEC lesion score (Fig. 2(A)) was significantly reduced in the LPSa-F $v$. control-F group $(P<0 \cdot 05)$. The control-C pigs lost less weight after birth (32 (SEM 19) g) than the control-F (115 (sEm 13) g) and LPSa-F pigs (97 (sEm 12) g, both $P<0.05$ ) and had lower relative liver weight (25.7 (SEm 0.6) v. $30 \cdot 6$ (SEM 1.1) g/kg (LPSa-F) and 30.8 (SEM 0.8) g/kg (control-F), both $P<0 \cdot 05$ ). Otherwise, relative organ weights and relative length of the small intestine did not differ among the three groups. Lung density was significantly higher in the control$\mathrm{F}$ pigs than in the control-C and LPSa-F pigs, which did not differ (0.83 (SEM 0.02) v. 0.77 (SEM 0.02) and 0.78 (SEM $0 \cdot 02) \mathrm{g} / \mathrm{ml}$, respectively; Fig. 2(D)).

Blood gas values at birth and at $6 \mathrm{~h}$ were not different among the three treatment groups, but at euthanasia, pigs with NEC, compared with healthy pigs, showed marked acidosis with low pH (7.01 (sem 0.12) $v \cdot 7 \cdot 34$ (SEM 0.02)), low $\mathrm{HCO}_{3}$ levels (9.0 (SEM 2.0) v. $25 \cdot 2(\operatorname{sem} 1 \cdot 2) \mathrm{mmol} / \mathrm{l})$, and high lactate (9.2 (SEM 2.3) v. $1.6($ SEM $0 \cdot 2) \mathrm{mmol} / \mathrm{l})$ and $\mathrm{K}$ levels $(6 \cdot 3$ (SEM 1.1) v. 3.9 (SEM $0 \cdot 1) \mathrm{mmol} / \mathrm{l})$. At birth and $6 \mathrm{~h}$, only low haptoglobin levels could be detected, but the levels increased thereafter and were significantly higher in formula-fed $v$. colostrum-fed pigs at $2 \mathrm{~d}$ (Fig. 2(E)). 
Table 2. Selected values of clinical, gut structural and functional indices for pigs given intramuscular injections with saline or lipopolysaccharide (LPS) and fed formula or colostrum

(Mean values with their standard errors)

\begin{tabular}{|c|c|c|c|c|c|c|c|c|}
\hline & \multicolumn{8}{|c|}{ Treatment } \\
\hline & \multicolumn{2}{|c|}{ LPS-im-F } & \multicolumn{2}{|c|}{ Saline-im-F } & \multicolumn{2}{|c|}{ LPS-im-C } & \multicolumn{2}{|c|}{ Saline-im-C } \\
\hline & Mean* & SEM & Mean $^{*}$ & SEM & Mean* & SEM & Mean* & SEM \\
\hline Weight loss† (g) & 98 & 19 & 126 & 19 & 9 & 27 & 51 & 25 \\
\hline NEC score & $2 \cdot 1$ & 0.4 & $2 \cdot 0$ & 0.4 & 1.0 & 0.0 & 1.0 & 0.0 \\
\hline SI weight§ (g/kg) & 29.4 & 3.4 & $31 \cdot 7$ & 1.5 & $28 \cdot 3$ & $2 \cdot 8$ & $26 \cdot 7$ & $5 \cdot 5$ \\
\hline Colon weight§ $(\mathrm{g} / \mathrm{kg})$ & 8.2 & 1.0 & $7 \cdot 0$ & 0.9 & 8.2 & 0.7 & 8.4 & 0.5 \\
\hline Liver weight§ $(\mathrm{g} / \mathrm{kg})$ & $30 \cdot 4$ & 1.0 & 30.9 & $1 \cdot 1$ & $26 \cdot 2$ & $1 \cdot 1$ & $25 \cdot 2$ & 0.7 \\
\hline Lung density (g/ml) & 0.84 & 0.02 & 0.83 & 0.02 & 0.79 & 0.03 & 0.75 & 0.03 \\
\hline Sucrase\| $(\mathrm{U} / \mathrm{g})$ & 0.15 & 0.03 & 0.19 & 0.03 & 0.19 & 0.01 & 0.15 & 0.02 \\
\hline Maltase $\|(\mathrm{U} / \mathrm{g})$ & 1.82 & 0.37 & 1.79 & 0.29 & $2 \cdot 27$ & 0.17 & 1.97 & 0.13 \\
\hline Lactase\| (U/g) & 8.48 & 1.75 & 7.93 & 1.45 & $22 \cdot 68$ & 2.68 & 18.44 & $2 \cdot 38$ \\
\hline$A p N \|(U / g)$ & $4 \cdot 29$ & 0.76 & $4 \cdot 26$ & 0.54 & 6.92 & 0.29 & 6.58 & 0.76 \\
\hline$A p A \|(U / g)$ & $2 \cdot 19$ & 0.41 & 2.34 & 0.27 & 3.17 & 0.15 & 2.85 & 0.33 \\
\hline DPP IV\| (U/g) & 0.89 & 0.11 & 1.03 & $0 \cdot 11$ & 1.60 & 0.06 & 1.62 & 0.30 \\
\hline Villusף $(\mu \mathrm{m})$ & 334 & 84 & 404 & 76 & 573 & 56 & 537 & 74 \\
\hline $\mathrm{pH}$ & $7 \cdot 2$ & 0.1 & $7 \cdot 2$ & 0.1 & 7.4 & 0.0 & 7.4 & 0.1 \\
\hline Lactate $^{\star \star}(\mathrm{mmol} / \mathrm{l})$ & $6 \cdot 1$ & 1.7 & $3 \cdot 2$ & 1.4 & 1.7 & 0.7 & 1.8 & 0.5 \\
\hline $\mathrm{HCO}_{3}{ }^{* \star}(\mathrm{mmol} / \mathrm{l})$ & $16 \cdot 5$ & 3.5 & $19 \cdot 4$ & $2 \cdot 5$ & $27 \cdot 8$ & 0.9 & $28 \cdot 1$ & $2 \cdot 3$ \\
\hline $\begin{array}{l}\text { LPS-im-F, formula-fed pig } \\
\text { LPS-im-C, colostrum-fe } \\
\text { injections; NEC, necrot } \\
\text { peptidase IV. } \\
\text { * Mean values were comp } \\
\text { none were found to be } \\
\dagger \text { Loss of body weight fror } \\
\text { † Mean lesion score acros } \\
\text { \& Organ weight relative to } \\
\| \text { Mean values for the pro } \\
\text { \ Villus height in the dista } \\
\star \star \\
\star \text { Values in the whole blo }\end{array}$ & $\begin{array}{l}\text { yiven intram } \\
\text { pigs given } \\
\mathrm{g} \text { enterocoli } \\
\text { d between } \\
\text { nificant (AN } \\
\text { irth to killin } \\
\text { ive gastroin } \\
\text { dy weight a } \\
\text { lal, mid and } \\
\text { nall intestin }\end{array}$ & $\begin{array}{l}\text { cular LPS } \\
\text { ramuscul } \\
\text {; SI, sma } \\
\text { e two gro } \\
\text { A). } \\
\text { stinal regi } \\
\text { illing. } \\
\text { stal small }\end{array}$ & $\begin{array}{l}\text { ections; sa } \\
\text { PS injecti } \\
\text { estine; ApN } \\
\text { of formula }\end{array}$ & $\begin{array}{l}\text { e-im-F, fo } \\
\text {; Saline-i } \\
\text { aminopep } \\
\text { d pigs an }\end{array}$ & $\begin{array}{l}\text { la-fed pigs } \\
\text { colostrur } \\
\text { e N; ApA, } \\
\text { tween the }\end{array}$ & $\begin{array}{l}\text { en intran } \\
\text { d pigs g } \\
\text { inopeptid } \\
\text { groups }\end{array}$ & $\begin{array}{l}\text { cular saline } \\
\text { intramusc } \\
\text { A; DPP IV } \\
\text { olostrum-fe }\end{array}$ & $\begin{array}{l}\text { ections; } \\
\text { r saline } \\
\text { peptidyl } \\
\text { gs, and }\end{array}$ \\
\hline
\end{tabular}

\section{Mucosal integrity, structure and digestive function}

Intestinal permeability was threefold higher in the control-F pigs, relative to the control-C pigs $(P=0.08)$, with intermediate values for the LPSa-F group (Fig. 2(C)). Villus height in the distal small intestine showed the opposite trend with highest values in the control-C pigs, lowest values in the control-F pigs $(P<0.05$ relative to control-C) and intermediate values in the LPSa-F pigs (Fig. 2(B)). Likewise, the villus height:crypt depth ratio was significantly higher in colostrum-fed pigs (control-C: $5 \cdot 1$ (SEM 0.4)) than in formula-fed pigs (3.9 (SEM $0 \cdot 4$ ) in the control-F and 4.3 (SEm 0.3) in the LPSa-F groups, both $P<0 \cdot 01)$. Compared with healthy formula-fed pigs, formula-fed pigs with NEC had shortened villi (200 (SEM 49) $v$. 531 (SEM 31) $\mu \mathrm{m}$ ), lowered crypts (65 (SEM 10) v. 109 (SEM 5)) and a thinner layer of non-mucosal tissue (88 (sem 6) $v$. 105 (sem 3) $\mu \mathrm{m}$, all $P<0 \cdot 01$ ).

Except for sucrase activity, which was highest in the LPSa-F pigs $(0.22$ (SEM 0.03$) v .0 \cdot 15$ (SEM 0.02$) \mathrm{U} / \mathrm{g}$ in the proximal region and $0.36(\operatorname{sem} 0.09) \quad v .0 .23(\operatorname{sem} 0.03) \mathrm{U} / g$ in the middle region, both $P<0 \cdot 01$ ) (where $1 \mathrm{U}=1 \mu \mathrm{mol}$ hydrolysed substrate per min at $37^{\circ} \mathrm{C}$ ), activity of disaccharidases and peptidases across all three regions of the small intestine was highest in colostrum-fed pigs (Fig. 3). LPSa increased the mean lactase, aminopeptidase $\mathrm{A}$ and $\mathrm{N}$ activities of formula-fed pigs, but the effects reached statistical significance only for lactase activity in the proximal and middle intestine
(14.2 (sem 1.9) for LPSa-F pigs $v$. 11.2 (sem 1.8) U/g for control-F pigs, $P<0.05)$.

\section{Mucosal immune parameters}

Based on mRNA microarray analysis of the small intestine, treatment group comparisons revealed pairwise differences in gene expression due to prenatal treatments, postnatal diet regimens and disease states. Due to relatively high tissue complexity and small differences in expression levels, we judged that the microarray analysis was too insensitive to detect quantitatively the up- or down-regulation of individual genes. We therefore used the total number of differentially expressed genes in the intestinal and hepatic tissue as the main outcome measure for specific group comparisons. These analyses showed that type of diet (formula or colostrum) had a greater influence on the number of differentially expressed genes compared with the presence or absence of LPSa treatment, as six intestinal genes were differentially expressed between the LPSa-F and control-F pigs, while thirty-three genes were differentially regulated between the control-C and control-F groups (Fig. 4(A), $P<0 \cdot 05$ ). Mainly genes involved in apoptosis, inflammation and acute-phase responses in the small intestine were affected by formula-feeding. LPSa administration appeared to compensate for the adverse effects of formula, since only seventeen intestinal genes were differentially regulated between the LPSa-F and control-C pigs 
(A)

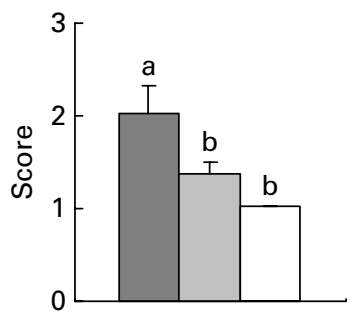

(B)

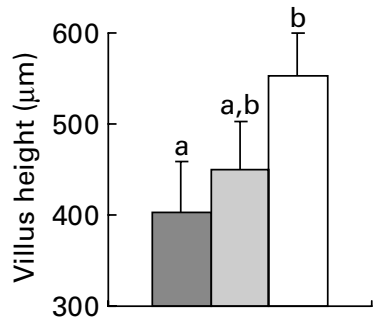

(C)

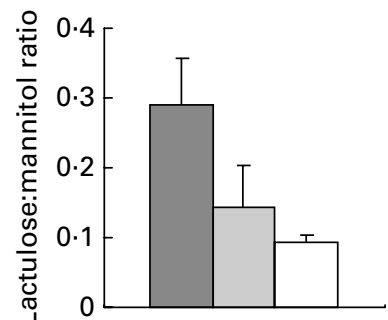

(D)

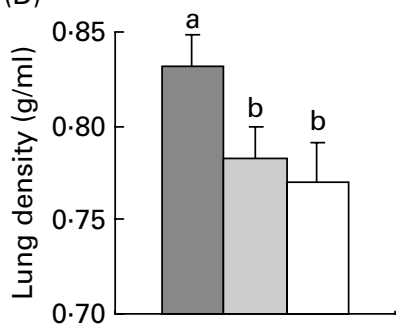

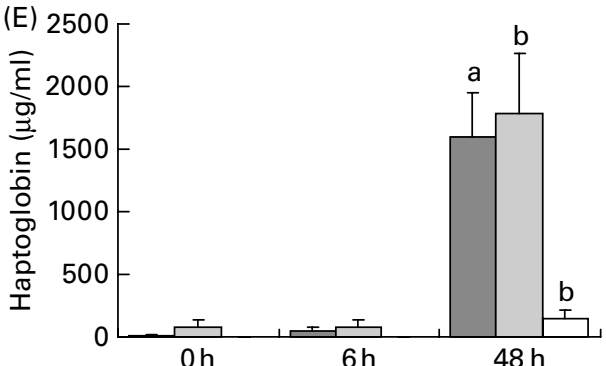

Fig. 2. (A) Necrotising enterocolitis lesion score, (B) villus height in the distal small intestine, (C) intestinal permeability as indicated by urinary lactulose:mannito ratio, (D) lung density and (E) plasma haptoglobin levels at birth, $6 \mathrm{~h}$ after birth and at the time of tissue collection. Values are means, with their standard errors represented by vertical bars. ${ }^{a, b}$ Mean values with unlike letters were significantly different between groups $(P<0.05)$. $\square$, Control-formula; $\square$, intra-amniotic lipopolysaccharide; $\square$, control-colostrum.

(Fig. 4(A), $P<0 \cdot 05)$. The fifty-five genes differentially expressed between pigs with and without NEC showed that the presence of intestinal lesions influenced immune gene regulation even more than diets (Fig. 4(A)). Mainly genes involved in apoptosis, immune response and metabolism accounted for this difference. The following genes, or groups of genes, were affected when NEC-affected intestines were compared with healthy formula-fed intestines: angiopoietin 2, Bcl2-xL, fass-associating death domain, components in TLR pathways, IL, transforming growth factor b3 and its receptor, proteasome activator, endothelial NO synthase, complement components, haptoglobin, plasminogen activating factor, transferrin, apo 1, sugar transporters (GLUT and sodium-glucose-linked transporter 1), aminopeptidase A and N, lactate dehydrogenase-c and fatty acid-binding protein. Treatment group differences in the number of differentially regulated genes in the liver were

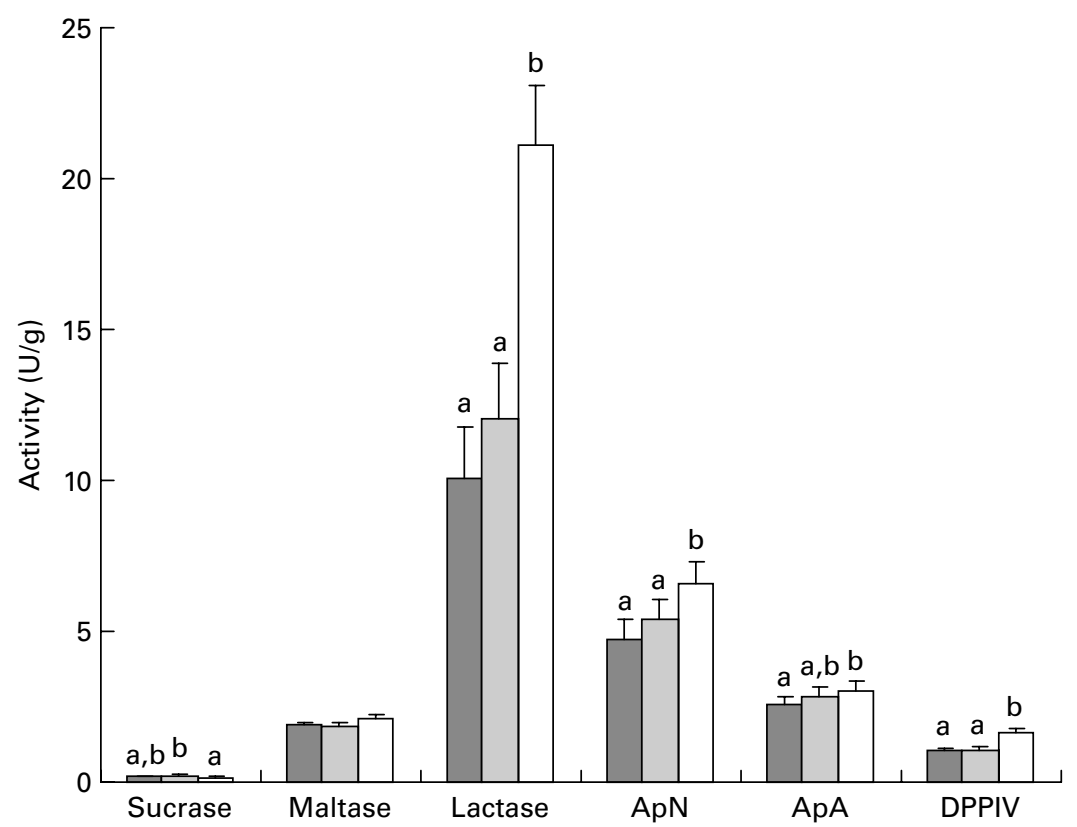

Fig. 3. Brush-border enzyme activities across three regions of the small intestine. Values are means, with their standard errors represented by vertical bars. ${ }^{a, b}$ Mean values with unlike letters were significantly different between groups $(P<0.05)$. ApN, aminopeptidase N; ApA, aminopeptidase A; DPP IV, dipeptidyl peptidase IV. $\square$, Control-formula; $\square$, intra-amniotic lipopolysaccharide; $\square$, control-colostrum. $1 \mathrm{U}=1 \mu \mathrm{mol}$ hydrolysed substrate per min at $37^{\circ} \mathrm{C}$. 
fewer than for the intestine, and acute-phase proteins dominated (Fig. 4(B)). Only twelve liver genes were differentially expressed between healthy and NEC formula-fed pigs, indicating minimal effects of NEC on hepatic immune genes. None of the included acute-phase proteins was differentially regulated between the LPSa-F and control-C pigs, neither in the intestine nor in the liver.

Immunoblots revealed a significantly higher expression of TLR- 4 in the control-C pigs compared with the two groups of formula-fed pigs, which did not differ (Fig. 5(A)). However, protein abundance of $\mathrm{I} \kappa \mathrm{B}$, the inhibiting protein of the proinflammatory transcription factor, $\mathrm{NF}-\kappa \mathrm{B}$, was higher in the control-C (14.7 (SEM 1.1) units) and the LPSa-F (16.4 (SEM $0 \cdot 8)$ units) pigs. IL-1 receptor-associated kinase-1 (IRAK1) and levels of activated NF- $\mathrm{BB}$ in nuclear extracts did not differ among the three groups (Fig. 5(B)).

\section{Discussion}

Uterine infections during pregnancy have been associated with increased risk of pre-term birth, infection and overall neonatal morbidity ${ }^{(1,22,23)}$. Some studies have reported elevated NEC incidence following prenatal infection, but results have been inconsistent ${ }^{(7-9)}$. The difficulties in reaching conclusions regarding the effects of bacterial exposure before birth may be explained by the different location, type and length of exposure in utero, and the multitude of differences in clinical variables ex utero, such as feeding and antibiotic regimens. After birth, stimulation of the TLR- 4 receptor by Gram-negative bacteria stimulates NEC development during the suckling period of rodents ${ }^{(24-28)}$, while in neonatal mice, Gram-negative exposure may provide enhanced immunological tolerance ${ }^{(5)}$. Thus, prenatal LPS stimulation due to intrauterine infections may affect postnatal NEC resistance. Against this background, we hypothesised that prenatal exposure to LPS would enhance postnatal gut development and NEC resistance in pre-term pigs by providing better tolerance to gut colonisation. Consistent with our hypothesis, we found that LPSa exposure for 3-5 d before pre-term delivery modestly reduced the severity of NEC lesions, villus atrophy, intestinal permeability and damage to brush-border enzyme activities following formula-feeding. The finding that the effects were most pronounced in the proximal intestine indicates that this region was more exposed to swallowed LPS

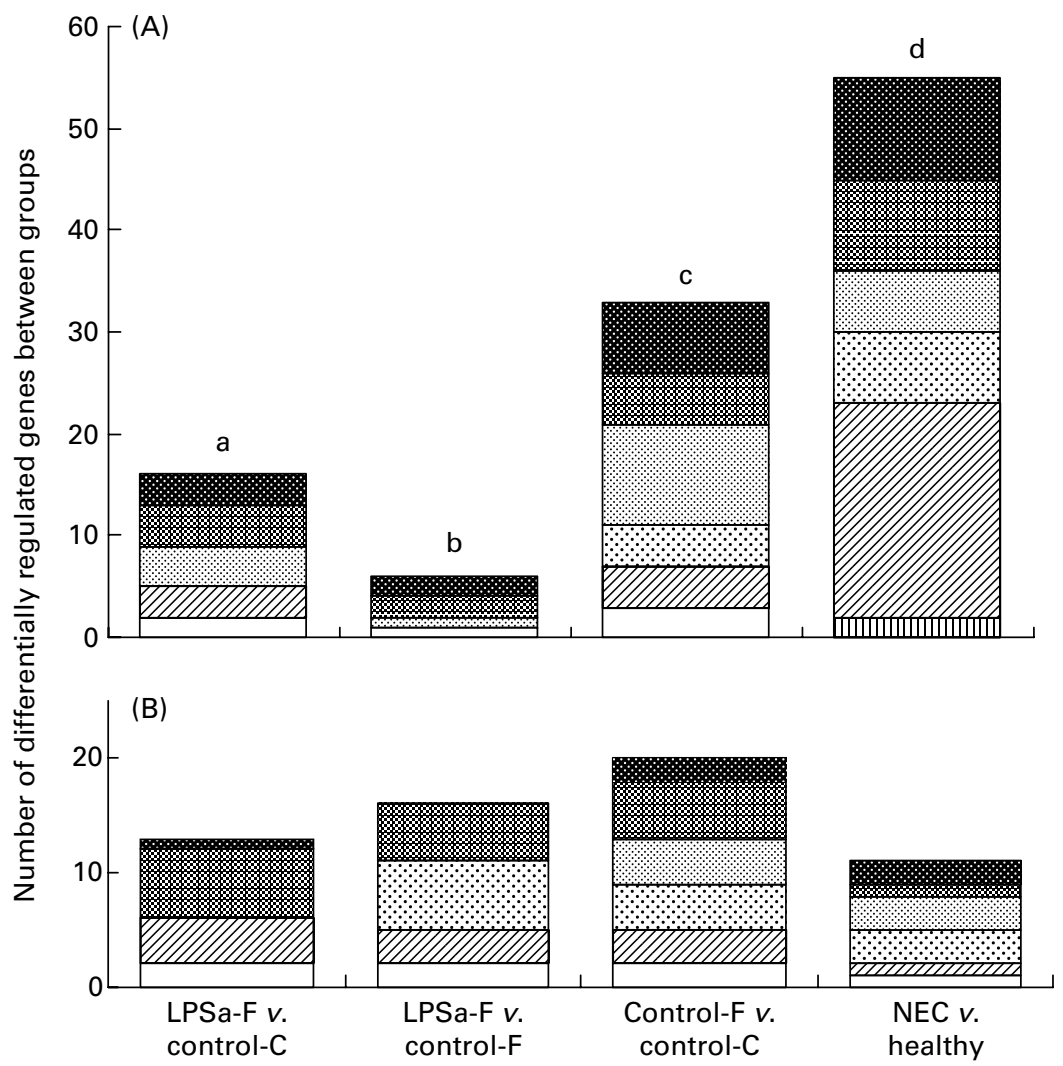

Fig. 4. Different functional groups and total number of genes that were differentially expressed in the (A) small intestine and (B) liver tissue between groups of pre-term pigs. The pairwise comparisons of gene expression between prenatal and postnatal treatments (control-formula (control-F), control-colostrum (control-C) and intra-amniotic lipopolysaccharide (LPSa)-F), and between pigs with and without necrotising enterocolitis (NEC), indicate the extent of tissue immune and metabolic responses to the various treatments. The number of differentially regulated genes between pigs exposed to intra-amniotic LPS (LPSa-F), and each of the other two groups, were significantly lower than between these two groups (control- $\mathrm{C} v$. control- $\mathrm{F}$, thirty-three differentially expressed genes, $P<0.05$ for both comparisons) and much lower than the number of differentially regulated genes between healthy pigs and pigs with NEC (fifty-five differentially regulated genes, $P<0.001)$. The numbers of differentially regulated genes in the liver between the groups were lower and not significantly different between different comparisons.

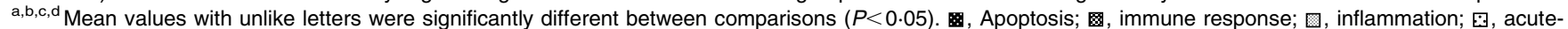
phase response; $\square$, metabolism; 皿, signal transduction; $\square$, other. 
(A)

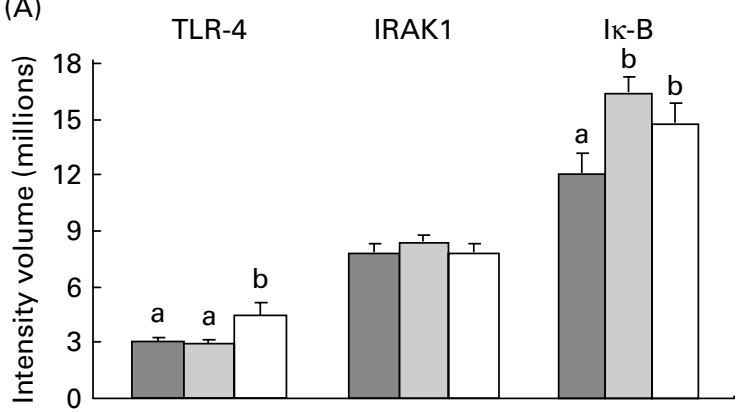

(B)

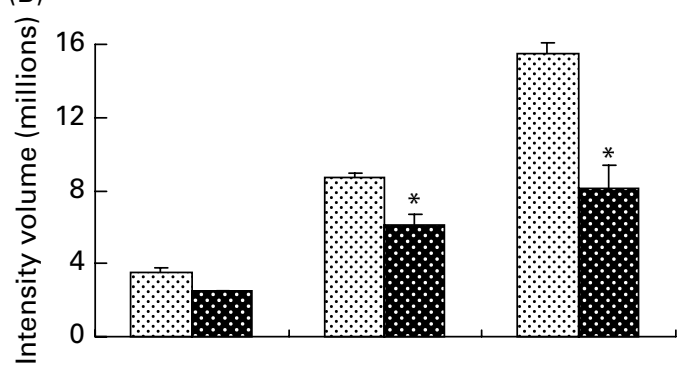

(C)

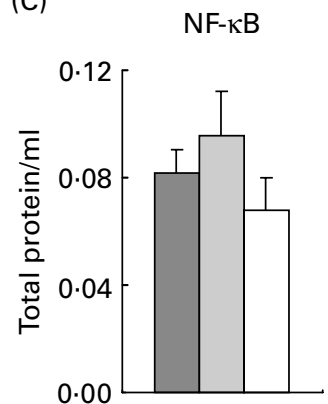

(D)

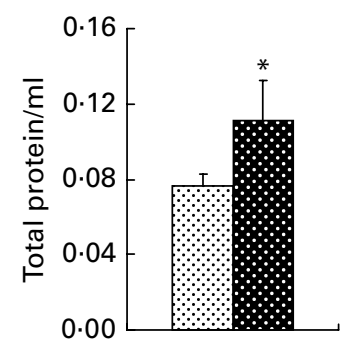

Fig. 5. Intestinal protein abundance for (A) toll-like receptor (TLR)-4, IL-1 receptor-associated kinase-1 (IRAK1) and IкB in response to treatment or (B) the presence of necrotising enterocolitis (NEC) as determined by Western blot analysis of intestinal extracts. Values are means, with their standard errors represented by vertical bars. Relative amount of $(C)$ active NF-KB among treatment groups and (D) between pigs with and without NEC from nuclear extracts, as determined by ELISA. ${ }^{a, b}$ Mean values with unlike letters were significantly different between treatment groups $(P<0.05)$. ${ }^{*}$ Mean values were significantly different between pigs with and without NEC $(P<0.05)$. $\square$, Control-formula; $\square$, LPSa, intra-amniotic lipopolysaccharide-formula; $\square$, control-colostrum; $\square$, healthy; , NEC.

than the more distal regions. Nevertheless, our analyses of the number of differentially expressed intestinal immune-related genes show that formula-fed pigs exposed prenatally to luminal LPS were indeed affected also in the distal intestine. Hence, the number of differentially regulated genes for this group was intermediate between the numbers for control formula- and colostrum-fed pre-term pigs. The distal part is usually the region mostly affected by NEC lesions ${ }^{(16-18)}$, possibly due to the high density of immune cells.

Our hypothesis that an intra-amniotic stimulation with Gram-negative LPS would induce immunological development of the immature gut epithelium was partly based on the clinical observations of decreased respiratory distress following prenatal infections ${ }^{(7-9)}$ and on the observed beneficial effects of LPSa injections on lung maturation and surfactant production in newborn lambs ${ }^{(10,12,29)}$. Intra-amniotic IL-1 administration also improved lung maturation and surfactant production in fetal rabbits ${ }^{(30)}$. In fetal lambs, the LPS effects on the fetal lung were independent of a rise in fetal cortisol levels $^{(31)}$, and also in the present study, circulating levels of cortisol did not differ among groups. In lambs, LPSa induced both systemic and local inflammation with increased inflammatory cells and cytokines in the cord blood, amniotic fluid and alveolar fluid ${ }^{(12)}$. This occurred as a direct result of luminal epithelial stimulation with bacterial compounds since lung maturation occurred only after LPS injection into the amniotic cavity, trachea or stomach, while systemic intra-peritoneal LPS injections caused severe acidosis or death ${ }^{(11)}$. The responses in fetal lambs were dose-dependent, and doses below $2 \mathrm{mg} / \mathrm{kg}$ resulted in inflammation without tissue or organ maturation $^{(29)}$, while fetal lambs survived after as much as $40 \mathrm{mg} / \mathrm{kg}$ into the amniotic cavity ${ }^{(31)}$. In the present study, the LPSa dose of $0.4 \mathrm{mg} / \mathrm{kg}$ was probably not sufficient to elicit a full inflammatory, tolerogenic and maturational response. This, combined with the variable ingestion of the amniotic fluid by each fetus, may explain that the luminal LPS administration had a limited and somewhat variable effect in the present study. On the other hand, the significant effects on lung density values (reflecting increased alveolar expansion) and intestinal structure and function, particularly in the proximal intestine (e.g. sucrase, lactase and villous integrity), support that LPSa had physiological effects. Better control of the dose, length and site of fetal LPS exposure will be important in future experiments to clarify how LPSa administration mimics the uterine, fetal and neonatal responses to Gram-negative chorioamnionitis.

Systemic LPS injections are commonly used to induce NEC in experimental NEC animal models ${ }^{(13,14,32)}$. As our fetal pigs injected intramuscularly with LPS did not differ from the saline control pigs, the chosen dose of $0.014 \mathrm{mg} / \mathrm{kg}$ LPS appeared insufficient to induce systemic inflammation and altered postnatal development. Nevertheless, acidosis, increased TNF- $\alpha$ and brain injury were the result of low LPS doses (0.005-0.015 mg, intravenously) to fetal lambs ${ }^{(33)}$, while $1 \mathrm{mg} / \mathrm{kg}$ caused severe acidosis and death ${ }^{(11)}$. In postnatal pigs, $0.2 \mathrm{mg} / \mathrm{kg}$ induced mild acidosis ${ }^{(34)}$, while higher doses to newborn pigs ( $2 \mathrm{mg} / \mathrm{kg}$, intravenously) resulted in decreased numbers of leucocytes and lesions similar to infant $\mathrm{NEC}^{(13)}$. We chose relatively low doses of LPS for both administration routes, considering that injection of 
multiple fetuses late in gestation is associated with a high risk of spontaneous abortion. Spontaneous signs of labour occurred for all sows within 3-5d of surgery, indicating that the modest LPS stimulation, combined with fetal surgery, was sufficient to advance parturition. Maternal anaesthesia and fetal surgery alone do not usually initiate parturition, as shown in our many earlier studies on fetal pigs at similar gestational ages $^{(17,35,36)}$.

The present study confirms earlier observations that cows' colostrum stimulates gut development and NEC resistance $^{(15,16)}$, probably via immunoregulatory, antibiotic or trophic compounds ${ }^{(37)}$. The effects of colostrum-feeding, relative to formula, were generally greater than those of prenatal LPS treatment. Beneficial effects of colostrum were also observed in newborn rats where the mother's milk rapidly reduced the high intestinal $\mathrm{NF}-\kappa \mathrm{B}$ activity ${ }^{(38)}$. On the other hand, formula-feeding stimulated NEC and maintained high TLR- 4 and NF- $\kappa \mathrm{B}$ activity with low levels of the inhibitory protein $\mathrm{I} \mathrm{B}^{(38)}$. In pre-term pigs, we have not found a consistent formula- and NEC-induced up-regulation of intestinal TLR-4 expression, and in the present study, TLR- 4 protein was elevated in the colostrum group. Likewise, maternal milk enhanced, rather than reduced, the TLR-4-mediated responses in adult and fetal enterocytes and leucocytes in vitro ${ }^{(39)}$. Immunoblotting revealed that protein abundance of $\mathrm{I} \kappa \mathrm{B}$, an inhibitory protein of the TLR-4-dependent NF-кB pathway, was elevated in the LPS-exposed and colostrum-fed pigs. Hence, the exact role of TLR- 4 protein and mRNA expression, and TLR-4-mediated inflammatory pathways in association with bacterial stimuli, pro-inflammatory diets and NEC remains controversial.

The results of the microarray analyses of gut and liver tissues indicated that diet exerted a main influence on the inflammatory processes, although LPSa injections also appeared to modify the number of differentially expressed genes. In general, gene regulation was less affected by diet and LPS exposure, than by the presence of NEC, as assessed by the number of differentially expressed genes. The semiquantitative nature of the microarray analysis precluded any detailed study of single genes. Intestinal genes related to both immune function and metabolic/digestive activities were affected, and the changes in intestinal gene expression were associated with only a few changes in expression for the same genes in the liver. Nevertheless, a systemic acutephase response was indicated by the increased plasma haptoglobin levels in formula-fed $v$. colostrum-fed pigs.

The pig represents an elegant animal model to investigate how the immature intestine is affected by systemic or luminal bacterial stimuli in utero. Extensive fetal manipulations are possible in the late gestation, and NEC develops spontaneously after pre-term birth and formula-feeding. We have shown that LPSa may enhance intestinal maturation, immunity and NEC resistance, although the effects at the present dose were modest compared with those of a NEC-protective diet such as cows' colostrum. More studies using different bacterial stimuli and varying doses and sites of bacterial exposure are required to better understand how prenatal bacterial products may affect the pre-term neonate, and thus influence the clinical interventions for infants being born prematurely following uterine and fetal infections.

\section{Acknowledgements}

The present study was supported by the Danish Strategic Research Council under the program of FØSU. We wish to thank Bente Synnetsvedt, Axel Kornerup Hansen, Malene Birck and Elin Skytte for their assistance with the animal procedures. We also thank Kristina Møller, Sophia Rasmussen, Joanna Amenuvor and Thomas Boye Pihl for their technical assistance with the RNA analyses. The authors have no conflicts of interest.

\section{References}

1. Aziz N, Cheng YW \& Caughey AB (2009) Neonatal outcomes in the setting of preterm premature rupture of membranes complicated by chorioamnionitis. J Matern Fetal Neonatal Med 22, 780-784

2. Seo K, McGregor JA \& French JI (1992) Preterm birth is associated with increased risk of maternal and neonatal infection. Obstet Gynecol 79, 75-80.

3. Ramsey PS, Lieman JM, Brumfield CG, et al. (2005) Chorioamnionitis increases neonatal morbidity in pregnancies complicated by preterm premature rupture of membranes. Am J Obstet Gynecol 192, 1162-1166.

4. Alexander JM, Gilstrap LC, Cox SM, et al. (1998) Clinical chorioamnionitis and the prognosis for very low birth weight infants. Obstet Gynecol 91, 725-729.

5. Lotz M, Gutle D, Walther S, et al. (2006) Postnatal acquisition of endotoxin tolerance in intestinal epithelial cells. J Exp Med 203, 973-984.

6. Claud EC, Zhang X, Petrof EO, et al. (2007) Developmentally regulated tumor necrosis factor- $\alpha$ induced nuclear factorkappaB activation in intestinal epithelium. Am J Physiol Gastrointest Liver Physiol 292, G1411-G1419.

7. Goldenberg RL, Andrews WW, Faye-Petersen OM, et al. (2006) The Alabama preterm birth study: corticosteroids and neonatal outcomes in 23- to 32-week newborns with various markers of intrauterine infection. Am J Obstet Gynecol 195, 1020-1024.

8. Sims EJ, Vermillion ST \& Soper DE (2002) Preterm premature rupture of the membranes is associated with a reduction in neonatal respiratory distress syndrome. Am J Obstet Gynecol 187, 268-272.

9. Fung G, Bawden K, Chow P, et al. (2003) Chorioamnionitis and outcome in extremely preterm infants. Ann Acad Med Singapore 32, 305-310.

10. Kallapur SG, Moss TJ, Ikegami M, et al. (2005) Recruited inflammatory cells mediate endotoxin-induced lung maturation in preterm fetal lambs. Am J Respir Crit Care Med 172, 1315-1321.

11. Newnham JP, Moss TJ, Kramer BW, et al. (2002) The fetal maturational and inflammatory responses to different routes of endotoxin infusion in sheep. Am J Obstet Gynecol 186, 1062-1068.

12. Newnham JP, Shub A, Jobe AH, et al. (2005) The effects of intra-amniotic injection of periodontopathic lipopolysaccharides in sheep. Am J Obstet Gynecol 193, 313-321.

13. Ewer AK, Al-Salti W, Coney AM, et al. (2004) The role of platelet activating factor in a neonatal piglet model of necrotising enterocolitis. Gut 53, 207-213. 
14. Giannone PJ, Nankervis CA, Richter JM, et al. (2009) Prenatal lipopolysaccharide increases postnatal intestinal injury in a rat model of necrotizing enterocolitis. J Pediatr Gastroenterol Nutr 48, 276-282.

15. Bjornvad CR, Thymann T, Deutz NE, et al. (2008) Enteral feeding induces diet-dependent mucosal dysfunction, bacterial proliferation, and necrotizing enterocolitis in preterm pigs on parenteral nutrition. Am J Physiol Gastrointest Liver Physiol 295, G1092-G1103.

16. Sangild PT, Siggers RH, Schmidt M, et al. (2006) Diet- and colonization-dependent intestinal dysfunction predisposes to necrotizing enterocolitis in preterm pigs. Gastroenterology 130, 1776-1792.

17. Bjornvad CR, Schmidt M, Petersen YM, et al. (2005) Preterm birth makes the immature intestine sensitive to feedinginduced intestinal atrophy. Am J Physiol Regul Integr Comp Physiol 289, R1212-R1222.

18. Van Haver ER, Sangild PT, Oste M, et al. (2009) Dietdependent mucosal colonization and interleukin-1beta responses in preterm pigs susceptible to necrotizing enterocolitis. J Pediatr Gastroenterol Nutr 49, 90-98.

19. Sorensen NS, Tegtmeier C, Andresen LO, et al. (2006) The porcine acute phase protein response to acute clinical and subclinical experimental infection with Streptococcus suis. Vet Immunol Immunopathol 113, 157-168.

20. Skovgaard K, Mortensen S, Boye M, et al. (2009) Hepatic gene expression changes in pigs experimentally infected with the lung pathogen Actinobacillus pleuropneumoniae as analysed with an innate immunity focused microarray. Innate Immun 16, 343-353.

21. Burrin DG, Stoll B, Guan X, et al. (2007) GLP-2 rapidly activates divergent intracellular signaling pathways involved in intestinal cell survival and proliferation in neonatal piglets. Am J Physiol Endocrinol Metab 292, E281-E291.

22. Goepfert AR, Andrews WW, Carlo W, et al. (2004) Umbilical cord plasma interleukin- 6 concentrations in preterm infants and risk of neonatal morbidity. Am J Obstet Gynecol 191, $1375-1381$

23. Satar M, Turhan E, Yapicioglu H, et al. (2008) Cord blood cytokine levels in neonates born to mothers with prolonged premature rupture of membranes and its relationship with morbidity and mortality. Eur Cytokine Netw 19, 37-41.

24. Leaphart CL, Cavallo J, Gribar SC, et al. (2007) A critical role for TLR 4 in the pathogenesis of necrotizing enterocolitis by modulating intestinal injury and repair. J Immunol 179, $4808-4820$

25. Jilling T, Simon D, Lu J, et al. (2006) The roles of bacteria and TLR4 in rat and murine models of necrotizing enterocolitis. J Immunol 177, 3273-3282.
26. Claud EC, Lu L, Anton PM, et al. (2004) Developmentally regulated IkappaB expression in intestinal epithelium and susceptibility to flagellin-induced inflammation. Proc Natl Acad Sci U S A 101, 7404-7408.

27. Gribar SC, Sodhi CP, Richardson WM, et al. (2009) Reciprocal expression and signaling of TLR4 and TLR9 in the pathogenesis and treatment of necrotizing enterocolitis. J Immunol 182, 636-646.

28. Nanthakumar NN, Fusunyan RD, Sanderson I, et al. (2000) Inflammation in the developing human intestine: a possible pathophysiologic contribution to necrotizing enterocolitis. Proc Natl Acad Sci U S A 97, 6043-6048.

29. Kramer BW, Moss TJ, Willet KE, et al. (2001) Dose and time response after intraamniotic endotoxin in preterm lambs. $\mathrm{Am}$ J Respir Crit Care Med 164, 982-988.

30. Bry K, Lappalainen U \& Hallman M (1997) Intraamniotic interleukin-1 accelerates surfactant protein synthesis in fetal rabbits and improves lung stability after premature birth. $J$ Clin Invest 99, 2992-2999.

31. Jobe AH, Newnham JP, Willet KE, et al. (2000) Endotoxininduced lung maturation in preterm lambs is not mediated by cortisol. Am J Respir Crit Care Med 162, 1656-1661.

32. Chan KL, Wong KF \& Luk JM (2009) Role of LPS/CD14/ TLR4-mediated inflammation in necrotizing enterocolitis: pathogenesis and therapeutic implications. World J Gastroenterol 15, 4745-4752.

33. Duncan JR, Cock ML, Suzuki K, et al. (2006) Chronic endotoxin exposure causes brain injury in the ovine fetus in the absence of hypoxemia. J Soc Gynecol Investig 13, 87-96.

34. Groner JI (1997) Endotoxin and transient hypoxia cause severe acidosis in the piglet. J Pediatr Surg 32, 1123-1125.

35. Petersen YM, Burrin DG \& Sangild PT (2001) GLP-2 has differential effects on small intestine growth and function in fetal and neonatal pigs. Am J Physiol Regul Integr Comp Physiol 281, R1986-R1993.

36. Sangild PT, Schmidt M, Elnif J, et al. (2002) Prenatal development of gastrointestinal function in the pig and the effects of fetal esophageal obstruction. Pediatr Res 52, 416-424.

37. Playford RJ, MacDonald CE \& Johnson WS (2000) Colostrum and milk-derived peptide growth factors for the treatment of gastrointestinal disorders. Am J Clin Nutr 72, 5-14.

38. De Plaen IG, Liu SX, Tian R, et al. (2007) Inhibition of nuclear factor-kappaB ameliorates bowel injury and prolongs survival in a neonatal rat model of necrotizing enterocolitis. Pediatr Res 61, 716-721.

39. LeBouder E, Rey-Nores JE, Rushmere NK, et al. (2003) Soluble forms of Toll-like receptor (TLR)2 capable of modulating TLR2 signaling are present in human plasma and breast milk. J Immunol 171, 6680-6689. 